\title{
O pesquisador na escola experimental de primatas: de experimentador a programador de contingências
}

\author{
Romariz da Silva Barros \\ Olavo de Faria Galvão \\ Aline Cardoso Rocha \\ Universidade Federal do Pará
}

\begin{abstract}
RESUMO
O principal objetivo deste trabalho é mostrar mudanças de orientação metodológica na condução dos experimentos realizados em um laboratório dedicado à pesquisa sobre controle de estímulos com primatas. O comportamento do pesquisador foi abordado em quatro experimentos desenvolvidos nessa unidade de pesquisa. Enquanto tomada de decisões, o comportamento do pesquisador, de início controlado enfaticamente pelo plano experimental com ênfase no controle pelo procedimento, passou a se mostrar progressivamente mais sensível ao desempenho dos sujeitos, com ênfase no controle pelos resultados. Ao longo do nosso trabalho, a reconstrução de passos do procedimento, adicionando e removendo fases em relação ao plano original, se tornou mais provável. Essas mudanças na orientação metodológica estão diretamente implicadas na alteração do nome da referida unidade de pesquisa para Escola Experimental de Primatas, na medida em que os procedimentos de pesquisa passam a ser vistos como condições de ensino.
\end{abstract}

Palavras-chave: metodologia de pesquisa; comportamento do pesquisador; planejamento experimental em função de resultados.

\section{ABSTRACT \\ Researcher in the experimental school for primates: from experimenter to contingency programmer}

The main purpose of the present work is to show changes in the methodological orientation conducting experiments in a laboratory dedicated to stimulus control research in primates. The researcher behavior was analyzed in four experiments conducted in that research unity. As decision making, the researcher behavior was initially emphatically controlled by the experimental plan, with emphasis in the control by the procedure, and then became progressively more sensitive to the subject's performance, with emphasis in the control by the results. Along our work, rebuilding the steps of the procedure, adding or subtracting phases from original plan became more likely. These changes in the methodological orientation are directly linked to the change of the name of the referred research unity to Experimental School for Primates, as the research procedures began to be viewed as teaching conditions.

Keywords: research methodology; researcher behavior; results feedback on experimental design.

Como salientou Luna (1997), a realidade a ser pesquisada é maior, mais complexa e diversificada do que a qualquer tipo de formalização didática que se possa fazer sobre a atividade do pesquisador, de maneira que é muito difícil a tarefa de estabelecer parâmetros e limites para delimitar o que seja pesquisar. Para Luna, o papel do pesquisador é o de um "intérprete" da realidade pesquisada, de acordo com os ins- trumentos característicos de seu referencial teóricometodológico.

Numa visão tradicional de metodologia de pesquisa científica, o pesquisar é descrito como uma sequiência de passos logicamente organizados através dos quais uma pergunta pode ser respondida cientificamente. Nota-se uma ênfase grande no rigor da preparação de um bom plano experimental (no caso das pesquisas que lançam mão do método experimental) e na aplica- 
ção do procedimento elaborado. Mudanças de percurso provenientes, por exemplo, de circunstâncias geradas na aplicação do plano podem soar como inadequadas.

Examinando parte da literatura sobre metodologia de pesquisa em Psicologia, é possível verificar que raramente os diferentes autores deixam de reconhecer a importância da criatividade do pesquisador na condução da pesquisa ou a necessidade de se fugir do plano de pesquisa original. Em alguns casos, entretanto, essas afirmações se aproximam de um mero jargão, dado que tão logo tenha-se apresentado a possibilidade de desobediência ao plano original, descrevem-se roteiros ou etapas rígidas para o desenvolvimento de uma pesquisa experimental ou não-experimental (e.g., McGuigan, 1960/1976; Rudio, 1986/ 1992).

De acordo com Rudio (1986/1992),

\begin{abstract}
Embora enfatizando a valor da criatividade, convém lembrar que a pesquisa científica não pode ser fruto apenas da espontaneidade e intuição do indivíduo, mas exige submissão tanto aos procedimentos do método como aos recursos da técnica. O método é o caminho a ser percorrido, demarcado, do começo ao fim por fases ou etapas. (p. 15) [...] Pesquisa, no sentido mais amplo, é um conjunto de atividades orientadas para a busca de um determinado conhecimento. Afim de merecer o qualificativo de científica, a pesquisa deve ser feita de modo sistematizado. (p. 9)
\end{abstract}

Rudio (1986/1992), portanto, caracteriza o fazer ciência como um conjunto de atividades orientadas para a busca de conhecimento que devem ser realizadas de um modo previamente sistematizado. Rudio aponta, ainda que as "fases do método de pesquisa" seriam as que seguem: a) a formulação do problema da pesquisa; b) o enunciado de hipóteses; c) a coleta de dados e d) a análise e interpretação dos dados.

Também reconhecendo que ajustes quase sempre precisam ser feitos a um planejamento de pesquisa, mas não abrindo mão de descrever etapas bem definidas, McGuigan (1960/1976) enfatiza a necessidade de elaboração e seguimento de um plano rigoroso, fazendo uma sugestão minuciosa de quatorze passos a serem seguidos pelo experimentador para o desenvolvimento de um bom experimento (p. 68-83).

Em "Táticas da pesquisa científica", entretanto, Sidman (1960/1976) parte de um outro ponto de vista. Desde o prefácio desta obra, Sidman adverte:

O conceito de metodologia experimental que aqui emito não é revolucionário, nem novo. Mas devo prevenir o estudante, para que não espere um conjunto de regras e procedimentos experimentais a ser memorizado à maneira do manual clássico. (p. 8)

Sidman vai ainda além e acrescenta que...

\begin{abstract}
A busca da ciência é um assunto intensamente pessoal. Os pesquisadores não nos podem sempre contar por que, ou como, fazem aquilo que fazem, e o fato de suas conclusões serem corretas, na maioria das vezes, permanece um enigma mesmo para os muitos filósofos, lógicos e cientistas que devotaram boa parte do seu tempo e dos seus esforços a este problema. (p. 8)
\end{abstract}

Uma postura diferenciada no que diz respeito ao planejamento e condução da pesquisa e ainda em relação ao ensino de metodologia de pesquisa, portanto, pode ser encontrada em Sidman (1960/1976). Essa postura pode ser caracterizada essencialmente pela discordância em relação à apresentação de etapas, passos ou quaisquer outras formas de regras específicas para a construção de uma pesquisa. Ainda em "Táticas da pesquisa científica", Sidman afirma que

\begin{abstract}
Mesmo os que encontraram suas atividades aqui descritas, com o máximo de precisão, sentir-se-iam desconfortavelmente limitados se tivessem que proceder unicamente da forma que resumi. Nem a prática de experimentações, nem a avaliação dos seus resultados podem ser limitadas por quaisquer regras específicas: requisito que empresta uma certa nota de ironia a qualquer livro de metodologia experimental. (p. 8)
\end{abstract}

Seguindo uma orientação semelhante, Bachrach (1965/1974), apresenta algumas diretrizes para a metodologia de pesquisa (uma estrutura geral) visando a guiar, sem limitar, o comportamento do pesquisador, este definido como um "cuidadoso casual". Segundo Bachrach (1965/1974),

O pesquisador também deve ser um tanto casual, partir de um ponto de vista flexível, mas nem por isso menos alerta em relação à pesquisa, a qual pode propiciar ocasião para uma descoberta inesperada. Isto é o que Pasteur denominou de mente preparada, uma combinação de conhecimentos básicos acumulados e uma prontidão para perceber $o$ extraordinário. (p. 5)

Interação em Psicologia, Curitiba, jul./dez. 2005, (9)2, p. 201-214 
Para Bachrach (1965/1974), pesquisas científicas são desenvolvidas de maneira muito diferente daquelas que são descritas nos livros que se propõem a dizer como pesquisas científicas são feitas. Esta é o que Bachrach (1965/1974) convencionou chamar informalmente de sua primeira lei.

Quero dizer simplesmente que, em geral, os livros sobre pesquisa são afirmações de princípios gerais formalizados e apenas refletem, de uma maneira ideal, a realidade cotidiana da prática da pesquisa. Apresentam uma visão desprendida da ciência e pouco, se não nada, do prazer e da frustração. Em resumo, os livros sobre pesquisa são (para usar uma metáfora) como um traje de gala e a própria pesquisa é como uma roupa de trabalho (p. XIII).

Uma vez compreendidas essas duas maneiras de conceber ou ao menos apresentar o processo de desenvolvimento de pesquisa, torna-se oportuno acrescentar elementos que têm a ver diretamente com os objetivos do presente trabalho.

A unidade de pesquisa experimental destinada principalmente à análise do comportamento de primatas não-humanos que funciona no Departamento de Psicologia Experimental (DPE) na Universidade $\mathrm{Fe}-$ deral do Pará (UFPA), foi reativada em 1993, com o nome de Laboratório de Primatas, após alguns anos de inatividade. A partir de 1999, passou a ser intitulada Escola Experimental de Primatas.

Essa alteração do nome está diretamente relacionada a uma gradativa mudança de orientação metodológica ao longo da realização dos experimentos, partindo de uma postura mais próxima do pesquisar tradicional, com a definição rigorosa de etapas, para uma progressiva valorização de análises imediatas e constantes dos efeitos dos procedimentos aplicados pelo experimentador sobre o comportamento dos sujeitos.

Em analogia à idéia de procedimento como condição de ensino, a utilização do termo "escola" decorreu da sistematização e implementação de uma sucessão gradual de procedimentos que permitissem a construção de uma história experimental de pré-requisitos considerados necessários para a aquisição de desempenhos posteriores, partindo-se sempre do mais simples para o mais complexo (ver Galvão, Barros, Rocha, Mendonça \& Goulart, 2002).

O objetivo deste trabalho é apresentar dados que evidenciam a mudança de orientação no comportamento do pesquisador na unidade que hoje é chamada de Escola Experimental de Primatas ao longo das pesquisas com sujeitos não-humanos sobre controle de estímulos e formação de classes.

\section{Como atingir este objetivo?}

A alteração do nome da unidade de pesquisa, de Laboratório de Primatas, para Escola Experimental de Primatas foi tomada como um ponto referencial na descrição das principais modificações do comportamento do pesquisador com relação à aplicação dos procedimentos previstos nos planos de pesquisa.

O comportamento dos pesquisadores, definido como tomada de decisões em relação à manutenção ou modificação de etapas do procedimento experimental ao longo da pesquisa (Luna, 1997), foi avaliado em quatro experimentos, dois deles conduzidos antes e dois após a mudança de nome da unidade de pesquisa. A execução de cada plano experimental foi caracterizada como "enfaticamente controlada pelo procedimento programado" ou "enfaticamente controlada pelo resultado". A área de estudo dos quatro experimentos era o controle de estímulos e a formação de classes de estímulos, de acordo com os critérios definidos por Sidman e Tailby (1982).

Em todos os quatro experimentos foram utilizados como sujeitos macacos da espécie Cebus apella, os quais foram expostos a treinos e testes de relações entre estímulos. Os animais eram alojados em gaiolasviveiro externas ao ambiente de coleta de dados e em condições de alimentação, manutenção de saúde e manejo aprovadas junto ao Ibama. Além do aparato para alojamento e transporte dos animais para o ambiente experimental, o equipamento utilizado incluía uma câmara de condicionamento equipada com um computador PC $486100 \mathrm{Mhz}$ e tela sensível ao toque. Um software intitulado TREL (versão 2.1) era utilizado para a programação dos experimentos, apresentação dos estímulos e registro das respostas e latências. Como consequiência para respostas tidas como corretas, pelotas de comida (Noyes $190 \mathrm{mg}$ ) com aroma e sabor de banana eram fornecidas. Uma descrição mais detalhada dessas condições pode ser encontrada em Barros, Galvão e Fontes (1996) e Barros e Galvão (2003).

Nos Experimentos I e II foram utilizadas como estímulos as posições de quadrados brancos "desenhados" em fundo preto na disposição de matriz (3X3, quando 9 quadrados eram apresentados e matriz $4 X 4$, quando 16 quadrados eram apresentados). Nos experimentos III e IV, formas arbitrárias e cores foram usadas como estímulos.

A seguir serão apresentados dados descritivos dos procedimentos previstos nos planos originais dos quatro experimentos e comentários a respeito das modificações no plano introduzidas pelos experimentadores durante a execução de cada plano. Essa descrição 
visa a atender ao objetivo de caracterizar a execução do plano experimental como "enfaticamente controlada pelo procedimento previsto" ou "enfaticamente controlada pelos resultados parciais obtidos".

\section{Comportamento de pesquisar enfaticamente controlado pelo plano experimental}

Nesta sessão, descreveremos o desenvolvimento dos dois experimentos nos quais o comportamento dos pesquisadores foi considerado enfaticamente controlado pelo plano experimental.

O primeiro experimento (Dias, 1998) foi intitulado "Discriminações condicionais com posições como estímulo em Cebus apella". No estudo, foi treinada a discriminação condicional $\mathrm{AB}$ entre três estímulos de um Conjunto A e três do Conjunto B. Se o estímulo modelo era $\mathrm{A} 1$, as respostas de escolha de $\mathrm{B} 1$, e não de B2 ou B3, eram reforçadas; se A2, então escolhas de B2, e não de B1 ou B3, eram reforçadas; se A3, então escolhas B3 eram reforçadas e não de B1 ou B2. $\mathrm{O}$ objetivo do estudo foi averiguar se, uma vez treinadas essas relações condicionais, as relações condicionais simétricas (B1A1, B2A2 e B3A3) - Sidman e Tailby (1982) - podiam ser testadas ou treinadas através de repetição do teste com reforçamento e utilizando-se posições como estímulo. Esse procedimento é semelhante ao que foi utilizado por Sidman, Rauzin, Lazar, Cunningham, Tailby e Carrigan (1982) com estímulos visuais convencionais (linhas e cores).

Uma macaca da espécie Cebus apella (M05) serviu como sujeito. Ela havia participado anteriormente de treino de relações condicionais entre posiçõesestímulo em condições semelhantes às descritas no presente experimento.

A Figura 1 sumariza o procedimento do plano de pesquisa original e o procedimento que foi efetivamente adotado durante a execução do plano. Cada retângulo representa uma fase do experimento. Quando o critério de aquisição do desempenho para a fase era atingido, passava-se para a fase seguinte. Quando o critério não era obtido, em geral a fase era mantida. Os retângulos sem preenchimento correspondem ao plano original. Os retângulos com preenchimento em cinza apresentam as modificações introduzidas no plano.

No plano inicial, o procedimento programado era composto das seguintes fases:

a) Pré-treino: Modelagem da resposta de tocar a tela do computador.

b) Treino MTS AB: Treino das relações condicionais $\mathrm{AB}$ via procedimento de escolha de acordo com o modelo (Matching-To-Sample ou MTS). $\mathrm{O}$ desempenho final a ser obtido nesta fase do estudo era o animal selecionar um dos estímulos de comparação B1, B2 ou B3 condicionalmente à apresentação prévia dos estímulos modelo A1, A2 e A3, respectivamente.

c) Teste BA - simetria: Doze tentativas com as funções dos estímulos invertidas (nelas os estímulos modelo eram os do Conjunto $\mathrm{B}$ e os de comparação eram os do Conjunto A) foram apresentadas aleatoriamente distribuídas no meio das tentativas $\mathrm{AB}$ anteriormente treinadas. Das 12 tentativas de teste, havia 4 tentativas de cada uma das relações BA (B1A1, B2A2 e $\mathrm{B} 3 \mathrm{~A} 3$ ). Caso fosse atestada a propriedade simétrica, o experimento estaria encerrado.

d) Treino MTS BA: Caso os resultados do teste não evidenciassem a propriedade simétrica, iniciar-se-ia a tentativa de treinar as relações condicionais BA (esperadas pelo paradigma de simetria) através de repetições do bloco de teste BA.

Como é possível constatar pela Figura 1, o plano experimental foi executado à risca, conforme o procedimento acima descrito. Contudo, o bloco de teste BA foi repetido 20 vezes sem que o critério definido para encerramento dessa fase fosse atingido. Então, em adição ao plano original, passou-se ao treino das relações condicionais BA (B1A1, B2A2, B3A3) via procedimento de Matching-To-Sample (MTS) como na fase de Treino das relações condicionais AB. Para conclusão do treino, foram necessárias 12 sessões experimentais. Em seguida, foi feita uma verificação da linha de base AB (identificada na Figura 1 como "sondas" $\mathrm{AB}$ ) com um bloco de tentativas que tinha a mesma estrutura aqui descrita para o teste BA. Foram realizadas 17 repetições para obtenção do critério.

O outro estudo a ser descrito nesta secção do presente trabalho é continuidade da pesquisa sobre a posição enquanto estímulo em macacos Cebus apella publicado por Barros e Galvão (2003).

Em trabalhos anteriores (Barros, Galvão \& Fontes, 1996; Dias, 1998), as relações condicionais treinadas envolviam posições-estímulo definidas aleatoriamente no universo das nove posições em uma matriz $3 \times 3$. As relações entre os estímulos envolviam, portanto, movimentos em várias direções e sentidos (para cima, para baixo, esquerda e direita). Esse fato dificultava a interpretação dos resultados dos testes que, algumas vezes, evidenciavam relações consistentes entre estímulos, apesar de não serem as relações esperadas por simetria. Era difícil confirmar a suspeita, anterior- 

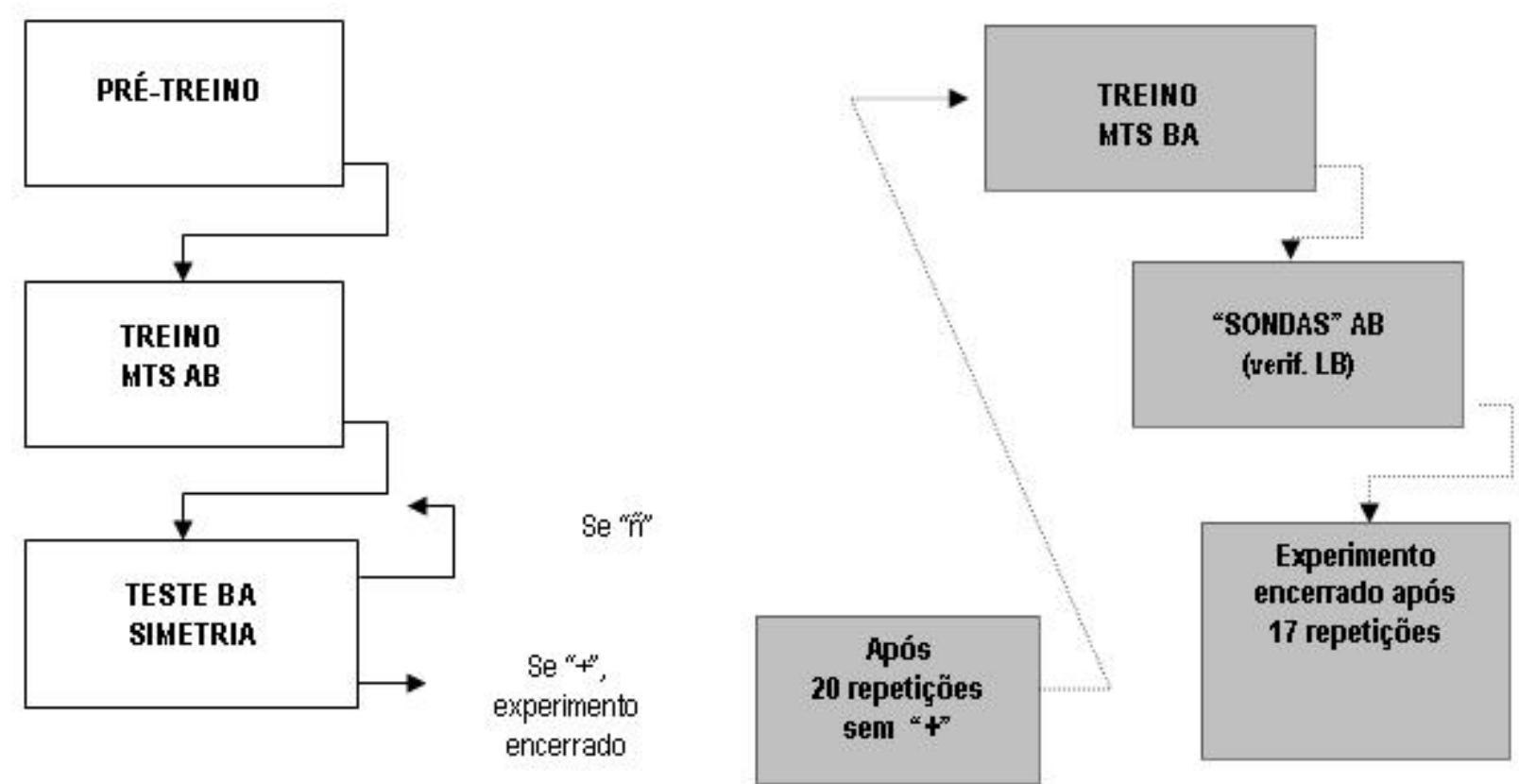

Figura 1. Plano de pesquisa inicialmente previsto e modificações introduzidas ao estudo de Dias (1998). Cada retângulo representa uma etapa do procedimento. Retângulos brancos representam etapas originalmente programadas. Retângulos com preenchimento em cinza representam modificações introduzidas ao plano original. Setas apontam a seqüência das etapas do procedimento. Para etapas de teste, "+" representa evidências positivas das relações testadas e "ñ" indica ausência de evidências dessas relações.

mente levantada, de que as relações obtidas no teste eram tentativas do sujeito responder da mesma maneira que o fazia durante o treino das relações condicionais de linha de base. Era necessário eliminar esse problema em experimentos subseqüentes. Além disso, Barros, Galvão e Fontes (1996) cogitaram a possibilidade de estudos subsequientes explorarem a emergência de simetria após o treino de vários exemplos de relações simétricas.

O objetivo do estudo de Barros e Galvão (2003) foi explorar as possibilidades acima apontadas repetindo o procedimento de Dias (1998) com duas modificações: 1) as relações condicionais entre posiçõesestímulo foram topograficamente organizadas (no sentido vertical ou horizontal, por exemplo) e 2) Em caso de não emergência de propriedades definidoras de equivalência, foi prevista a repetição do procedimento com novos conjuntos de posições-estímulo, de maneira a fornecer vários exemplos de relações simétricas.

Foram utilizados como sujeitos dois macacos da espécie Cebus apella. Um era macho (M06), sub-adulto e experimentalmente ingênuo. A outra, fêmea (M05), submetida anteriormente ao estudo de Dias (1998).

$\mathrm{O}$ procedimento envolveu inicialmente o treino de linha de base $\mathrm{AB}$ e teste de simetria BA, idêntico ao efetuado por Dias (1998). Caso a simetria não fosse atestada, os experimentadores planejaram efetuar o treino das relações condicionais esperadas pela propriedade de simetria, seguido do treino de nova linha de base e novo teste/treino de simetria, transitividade e simetria da transitividade, repetindo-se o procedimento com novas combinações de posições-estímulo.

A Figura 2 sumariza o procedimento utilizado por Barros e Galvão (2003), apresentando cada etapa. 


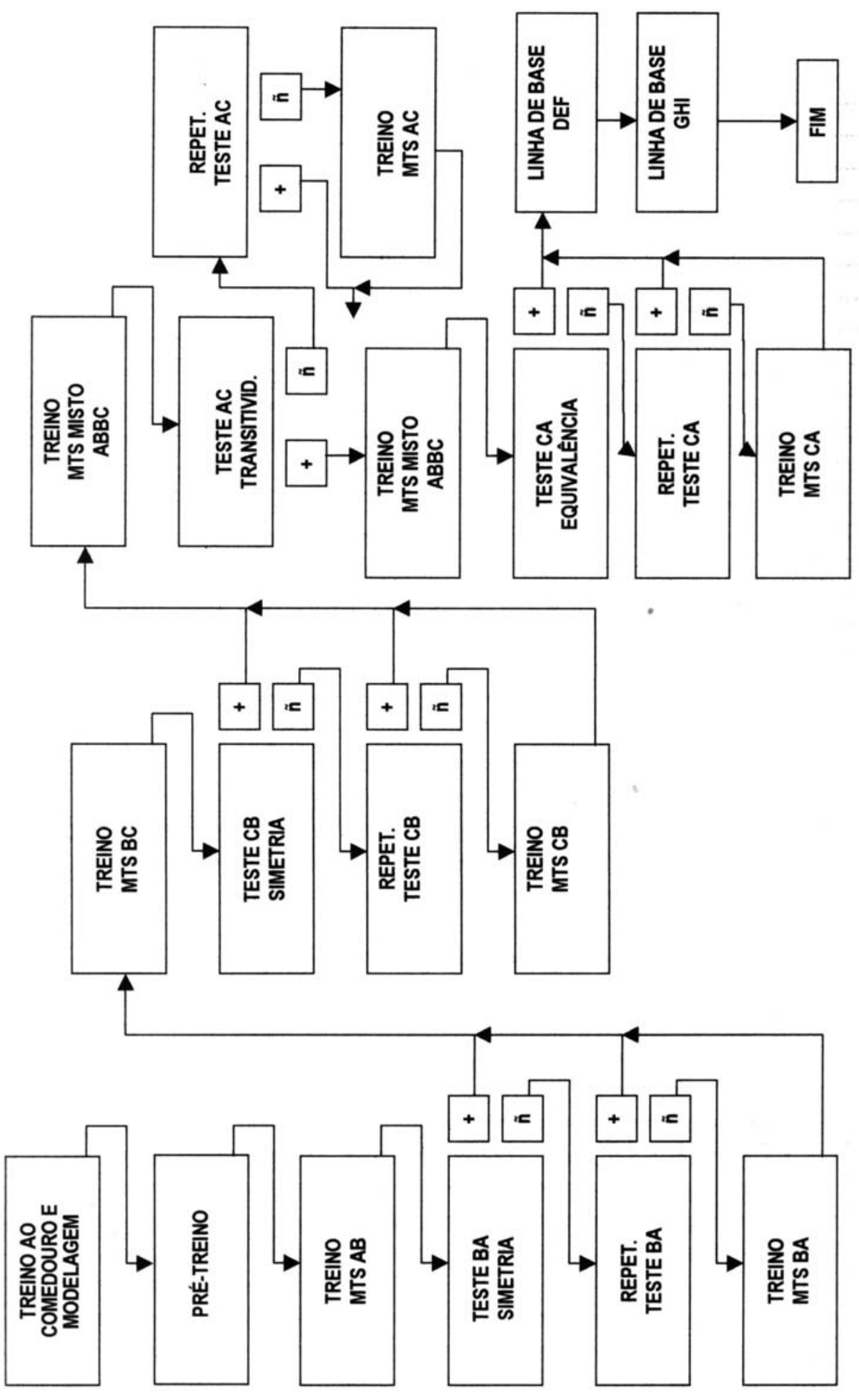

Figura 2. Plano de pesquisa previsto para estudo de Barros e Galvão (2003). Cada retângulo representa uma etapa do procedimento. Setas apontam

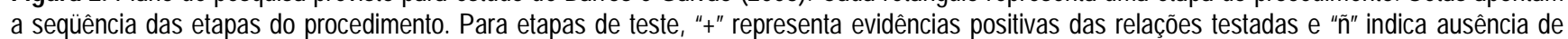
evidências dessas relações. 
O plano experimental incluía as seguintes etapas:

a) Treino ao comedouro e modelagem da resposta de tocar a tela do computador.

b) Pré-treino: reforçamento da resposta de tocar um quadrado branco apresentado na tela sensível do computador com uma pelota de comida em esquema de reforçamento contínuo. Respostas a qualquer outro estímulo não tinham conseqüências programadas.

c) Treino MTS AB: envolvia o treino das relações condicionais AB via procedimento de Matching-To-Sample (MTS), de maneira idêntica à de Dias (1998).

d) Teste BA simetria: o mesmo procedimento utilizado por Dias (1998) foi adotado no presente experimento.

e) Treino de novas linhas de base e teste de propriedades emergentes: caso os resultados do teste fossem positivos, os sujeitos seriam submetidos a treino de linha de base BC e teste de simetria $\mathrm{CB}$ além de teste de transitividade AC e simetria da transitividade (equivalência) $C A$ (ver Figura 2). Se a propriedade de simetria BA não fosse atestada, o previsto no plano experimental seriam as repetições do bloco de teste BA. Persistindo o resultado, seria realizado o treino da relação não emergente. Em seguida, proceder-se-ia ao treino $\mathrm{BC}$ e aos testes $\mathrm{CB}, \mathrm{AC}$ e CA, seguindo o mesmo procedimento acima para o caso de não obtenção da propriedade testada, conforme é apontado na Figura 2. Após isso, o plano experimental previa a exposição dos sujeitos a uma novas linhas de base (DEF e GHI) e testes correspondentes, seguindo o mesmo procedimento acima descrito.

O plano experimental previsto para o estudo de Barros e Galvão (2003) foi obedecido completamente à risca quando da execução da pesquisa. Todas as etapas previstas no plano e apresentadas na Figura 2 foram executadas. A execução do plano experimental relativo aos Experimentos I e II pode ser caracterizada como enfaticamente controlada pelo procedimento programado. Deve-se destacar o rigor com que os critérios estabelecidos eram cumpridos. Mesmo quando o desempenho do sujeito mostrava inadaptação ao procedimento, como no treino de simetria BA do Experimento I, o plano experimental foi mantido por 20 repetições deste bloco de treino. Diante do impasse, foi planejada uma continuidade para o experimento, redefinindo o procedimento de treino de simetria e incluindo uma verificação da linha de base original após esse treino.

Mesmo após essa inclusão, o comportamento do pesquisador continuou enfaticamente controlado pelo plano experimental, que conduziu exaustivas repetições dos blocos de verificação da linha de base $A B$, de modo semelhante ao que foi verificado no treino de simetria BA.

Observa-se portanto que, apesar das modificações incluídas no final do Experimento I, para ambos os experimentos, a ênfase ainda recaía no cumprimento do plano experimental, com poucas mudanças significativas e com um maior direcionamento para a repetição do procedimento programado, isto é, sem medidas remediativas nos treinos para a facilitação do desenvolvimento do desempenho do sujeito.

\section{Comportamento de pesquisar enfaticamente controlado pelo desempenho dos sujeitos}

O desenvolvimento dos dois planos de pesquisa a serem descritos a seguir permitem identificar que o comportamento do pesquisador esteve mais intensamente sob controle do desempenho dos sujeitos do que do plano experimental previamente traçado.

$\mathrm{O}$ primeiro destes dois planos a serem abordados, gerou o estudo de Barros, Galvão e Mcllvane (2002) que teve como objetivo treinar relações condicionais (arbitrárias ou baseadas na identidade), entre estímulos visuais convencionais (cores e formas arbitrárias) na ausência da correlação entre as posições dos estímulos (janela central versus janelas laterais) e sua função (modelo versus comparação). Essa correlação é típica do procedimento padrão de matching-tosample, uma vez que o estímulo modelo é usualmente apresentado em uma posição central e os estímulos de comparação, nas janelas laterais.

Esse estudo, como os dois anteriores, foi conduzido com o objetivo de verificar a possibilidade de obtenção de desempenho emergente, como a identidade generalizada e a simetria, a partir desse procedimento. O problema de pesquisa mais amplo continuou sendo a definição das condições necessárias para a formação de classes de estímulos em animais.

Foram sujeitos dois macacos da espécie Cebus apella machos sub-adultos. Um deles (M06) tinha sido submetido ao estudo de Barros e Galvão (2003). $\mathrm{O}$ outro (M07) era experimentalmente ingênuo.

$\mathrm{O}$ procedimento previsto pode ser descrito com o auxílio da Figura 3 (ver Figura 3). 


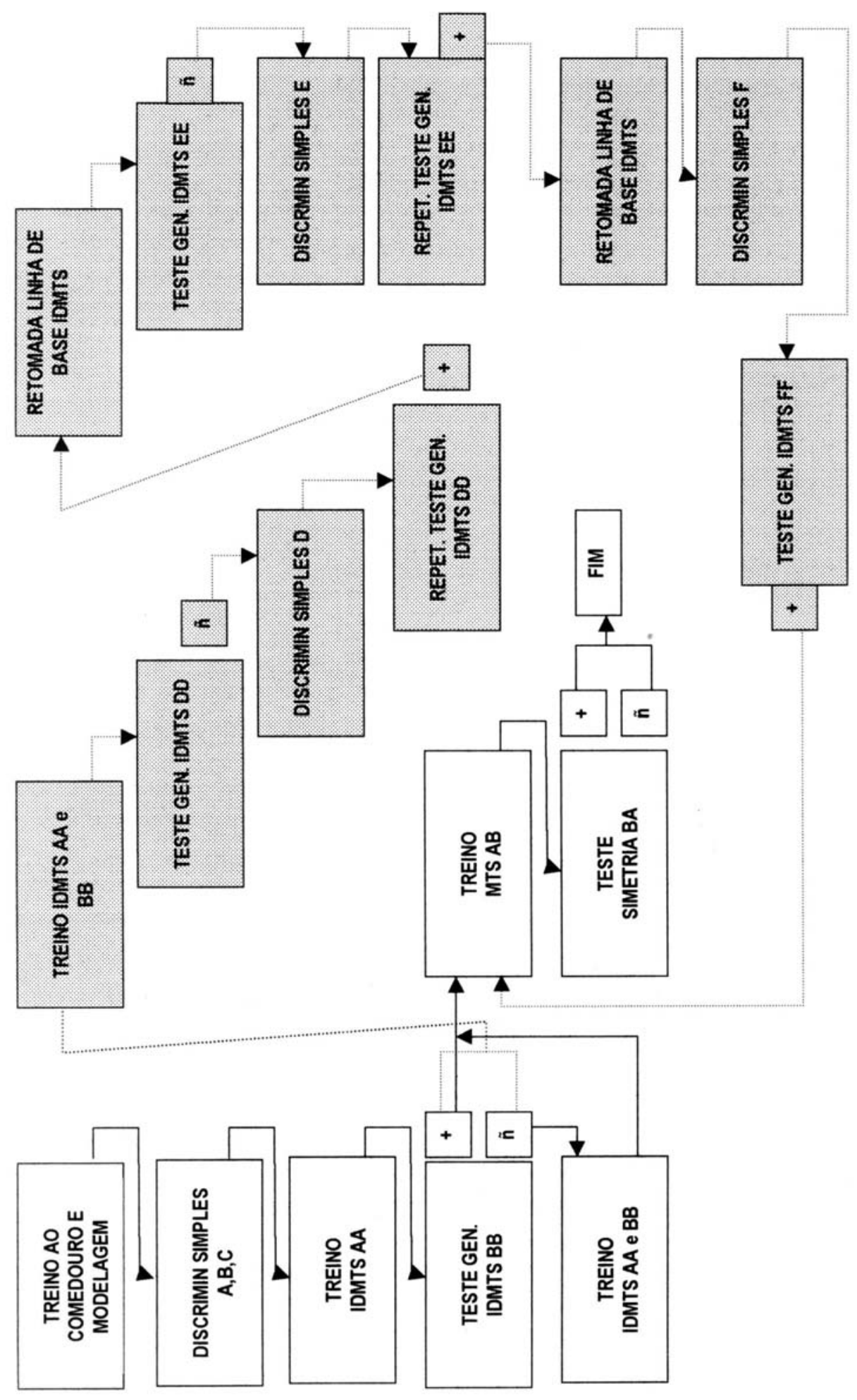

Figura 3. Plano de pesquisa previsto e modificações introduzidas ao estudo de Barros, Galvão e Mcllvane (2002). Cada retângulo representa uma etapa do procedimento. Retângulos brancos representam etapas originalmente programadas. Retângulos com preenchimento em cinza representam modificações introduzidas ao plano original. Setas apontam a seqüência das etapas do procedimento. Para etapas de teste, "+" representa evidências positivas das relações testadas e "ñ" indica ausência de evidências dessas relações. 

fases:

O plano experimental original previa as seguintes

a) Treino ao comedouro e modelagem: realizado de acordo com o procedimento descrito nos experimentos anteriores e ao qual foi submetido o sujeito M07.

b) Discriminações simples: treino de discriminações simples simultâneas com pares e trincas de estímulos dos Conjuntos A (formas arbitrárias), $\mathrm{B}$ (cores) e $\mathrm{C}$ (numerosidade). Esse treino foi conduzido com o objetivo inicial de selecionar estímulos que apresentavam baixa dificuldade (medida através do número de tentativas necessário para obtenção do critério) para serem discriminados simultaneamente pelos sujeitos.

c) Treino IDMTS AA: treino de relações condicionais (A1A1, A2A2, A3A3) baseadas na identidade entre o estímulo modelo e a comparação definida como correta, através do procedimento de escolha por identidade de acordo com o modelo ("identity matching-to-sample" - IDMTS).

d) Teste de identidade generalizada - IDMTS BB: com procedimentos e critérios idênticos aos descritos nos experimentos anteriores para os testes de simetria e outras propriedades emergentes.

e) Treino MTS AB e Teste de simetria BA: se os resultados do teste de identidade fossem positivos, seria efetuado o treino das relações arbitrárias $\mathrm{AB}$ e o teste de simetria $\mathrm{BA}$ e o experimento estaria encerrado; se negativo seria feito treino BB junto com o reestabelecimento da linha de base AA. Então, os sujeitos seriam submetidos aos treinos $\mathrm{AB}$ e ao teste de simetria e assim o experimento estaria encerrado.

O desenvolvimento do estudo de Barros, Galvão e McIlvane (2002) ficou parcialmente de acordo com o plano experimental durante as etapas descritas nos itens "a", "b", "c" e "d". Contudo, análises constantes do desempenho dos sujeitos revelaram a necessidade de eliminação de um dos estímulos do Conjunto A (a cor amarela, que resultou em generalização com a cor verde) e de todo o Conjunto $\mathrm{C}$ (numerosidades, em decorrência de generalização entre numerosidades próximas como 2 e 3). Essa tomada de decisão foi baseada nos resultados de treinos de discriminações simples entre pares de estímulos não previstos no plano original, como ocorrido com a introdução da numerosidade 7 para confirmar hipóteses levantadas a respeito da dificuldade dos sujeitos com esse conjunto de estímulos, especialmente com numerosidades próximas.
Após o teste de identidade generalizada, descrito no item "d" (ver também Figura 3), constatou-se que um dos sujeitos (M06) passou no teste enquanto que o outro (M07) não exibiu o desempenho de escolha de acordo com o modelo por identidade generalizada. Diante destes resultados, os pesquisadores se perguntaram quais seriam os resultados de testes de identidade generalizada, principalmente para o sujeito M06, se fossem apresentados nestes testes estímulos com os quais os sujeitos não apresentassem qualquer tipo de história experimental. Essa pergunta, ocasionada pelos resultados parciais obtidos até aquele momento, levou à suspensão do plano de pesquisa original e à programação de contingências capazes de respondê-la (ver Figura 3). Os sujeitos foram então submetidos a treino de escolha de acordo com o modelo por identidade com os estímulos A e B (linha de base) e a teste de identidade generalizada com estímulos completamente novos (Conjunto D - cores). Os resultados foram negativos para ambos os sujeitos.

Os experimentadores resolveram verificar se esses resultados negativos poderiam ser decorrentes de inadequações provenientes da escolha dos estímulos do Conjunto D (eles jamais tinham sido avaliados quanto a sua "discriminabilidade"). Foram, então, conduzidos treinos de discriminações simples com estes estímulos. Ambos os sujeitos discriminaram os estímulos com grande facilidade. Eles, então foram submetidos novamente ao teste de identidade generalizada DD. Ambos os sujeitos passaram no teste.

A essa altura os pesquisadores se encontravam cada vez mais atraídos pelos resultados parciais obtidos e mais distantes do plano de pesquisa original. Era necessário repetir esses testes com novos estímulos, apontavam os dados, para responder à seguinte pergunta: os resultados positivos seriam decorrentes da repetição do teste ou do treino de discriminações simples?

Os sujeitos foram submetidos a blocos de treino para recuperação da linha de base de escolha de acordo com o modelo por identidade e a testes desse desempenho com estímulos completamente novos, outra vez (Conjunto E - cores), como mostra a Figura 3. Os resultados foram negativos para ambos os sujeitos. Fez-se então necessário submeter os animais ao treino de discriminações simples com os estímulos do Conjunto "E".

Até aqui, as perguntas sugeridas pelos dados eram: 1) havia problemas de generalização com os estímulos? Ou 2) o treino de discriminações simples com os estímulos do Conjunto "E" seria suficiente para reverter os resultados negativos do teste de escolha por identidade generalizada? 
A continuidade do experimento revelou que, após o treino de discriminações simples simultâneas com os estímulos do Conjunto "E", ambos os sujeitos passaram no teste de escolha por identidade generalizada. Uma pergunta ainda foi levantada antes do retorno ao plano original de pesquisa: o que ocorreria se o treino de discriminações simples fosse feito antes do primeiro teste de identidade generalizada com estímulos novos (tal como foi feito no primeiro teste no qual passou o sujeito M06)? Em função dessa pergunta a linha de base de escolha por identidade generalizada foi recuperada e os sujeitos submetidos a treino de discriminações simples com os estímulos do Conjunto "F" (formas arbitrárias) antes do teste de escolha por identidade generalizada com estes estímulos. Ambos os sujeitos passaram no teste. Os dados agora davam clara indicação de que o treino de discriminações simples com um determinado conjunto de estímulos favorecia a obtenção do desempenho de escolha por identidade com esses estímulos.

Satisfeita a curiosidade provocada por dados tão claramente provocantes, os pesquisadores retornaram ao plano original (como mostra a Figura 3). Efetuouse o treino das relações condicionais arbitrárias com os estímulos A como modelos e os B como comparações e, em seguida, efetuaram o teste de propriedade simétrica BA. O desempenho de ambos os sujeitos mostrou evidências negativas de simetria. $\mathrm{O}$ experimento foi, então, encerrado.

Outro plano experimental, cuja condução sugere que o comportamento do pesquisador pode ser considerado como enfaticamente controlado pelo desempenho dos sujeitos, será descrito abaixo.

Parte das questões levantadas a respeito da construção do repertório generalizado de escolha por identidade ao modelo não puderam ser respondidas durante o estudo de Barros, Galvão e McIlvane (2002) antes que se passasse ao treino de relações condicionais arbitrárias. Havia dúvidas a respeito da adequação do uso de cores como estímulos e a respeito de um possível efeito de prática ao longo do experimento anterior. Os experimentadores ainda se perguntavam a respeito de que poderia ocorrer se fossem utilizados estímulos com maior dificuldade de discriminação, utilizados em pesquisas com participantes humanos (dificuldade de discriminação de estímulos como letras do alfabeto são comuns em experimentos com pessoas com desenvolvimento severamente retardado).

O plano experimental que acabou culminando no trabalho de Goulart, Mendonça, Barros e Galvão (2005) previa um retorno a essas questões. Seu objetivo inicial foi, portanto, replicar o estudo de Barros, Galvão e McIlvane (2002) com todos os conjuntos de estí- mulos constituídos de formas arbitrárias e repetindose o procedimento com $\mathrm{N}$ conjuntos de estímulos de maneira a poder evidenciar ou não o efeito de prática. Esse tipo de procedimento é comparável ao procedimento adotado no estudo de Barros e Galvão (2003) aqui descrito e que emprega o ensino de vários exemplos da mesma tarefa como "estratégia" para a obtenção de desempenhos generalizados

Foram utilizados como sujeitos os mesmos animais submetidos ao estudo de Barros, Galvão e Mcllvane (2002).

O procedimento é apresentado esquematicamente na Figura 4.

O plano experimental original previa as seguintes etapas:

a) Treino de IDMTS AA - o experimento iniciaria pela retomada do treino de escolha por identidade com o modelo (IDMTS) com os estímulos do Conjunto A, amplamente conhecidos pelos sujeitos (formas nomeadas pelo experimentador como "bola", "xis" e "xadrez").

b) Discriminação simples Conjunto B - treinos de discriminações simples e reversões com os estímulos novos (letras maiúsculas A, B e C). Em um bloco de tentativas, a letra A funcionava como S+ e as demais como S-. Assim que um critério de aquisição fosse obtido, o bloco era automaticamente interrompido e o experimentador iniciava um novo bloco com a letra B como $\mathrm{S}+\mathrm{e}$ as demais como S-. O mesmo procedimento era adotado para a apresentação da letra $\mathrm{C}$ como S+.

c) Teste/treino IDMTS AA e BB - Os sujeitos eram então submetidos a um bloco de treino de escolha por identidade ao modelo com os seis estímulos. A performance precisa dos participantes no pareamento por identidade com os estímulos do Conjunto B desde o início do treino seria considerada como evidência de identidade generalizada.

d) O plano experimental previa a continuidade do experimento com a repetição do mesmos procedimento com a apresentação de outros estímulos novos (Conjunto $\mathrm{C}$ compreendendo as letras "D", "E" e "F", Conjunto D, com as letras "G", "H" e "I" etc). Os experimentadores pretendiam comparar a aquisição do desempenho de escolha por identidade ao longo da exposição dos sujeitos a uma grande variedade de diferentes conjuntos de estímulos novos, podendo eventualmente considerar esse desempenho como emergente caso o critério estabelecido para treino fosse atingido desde as primeiras tentativas. 

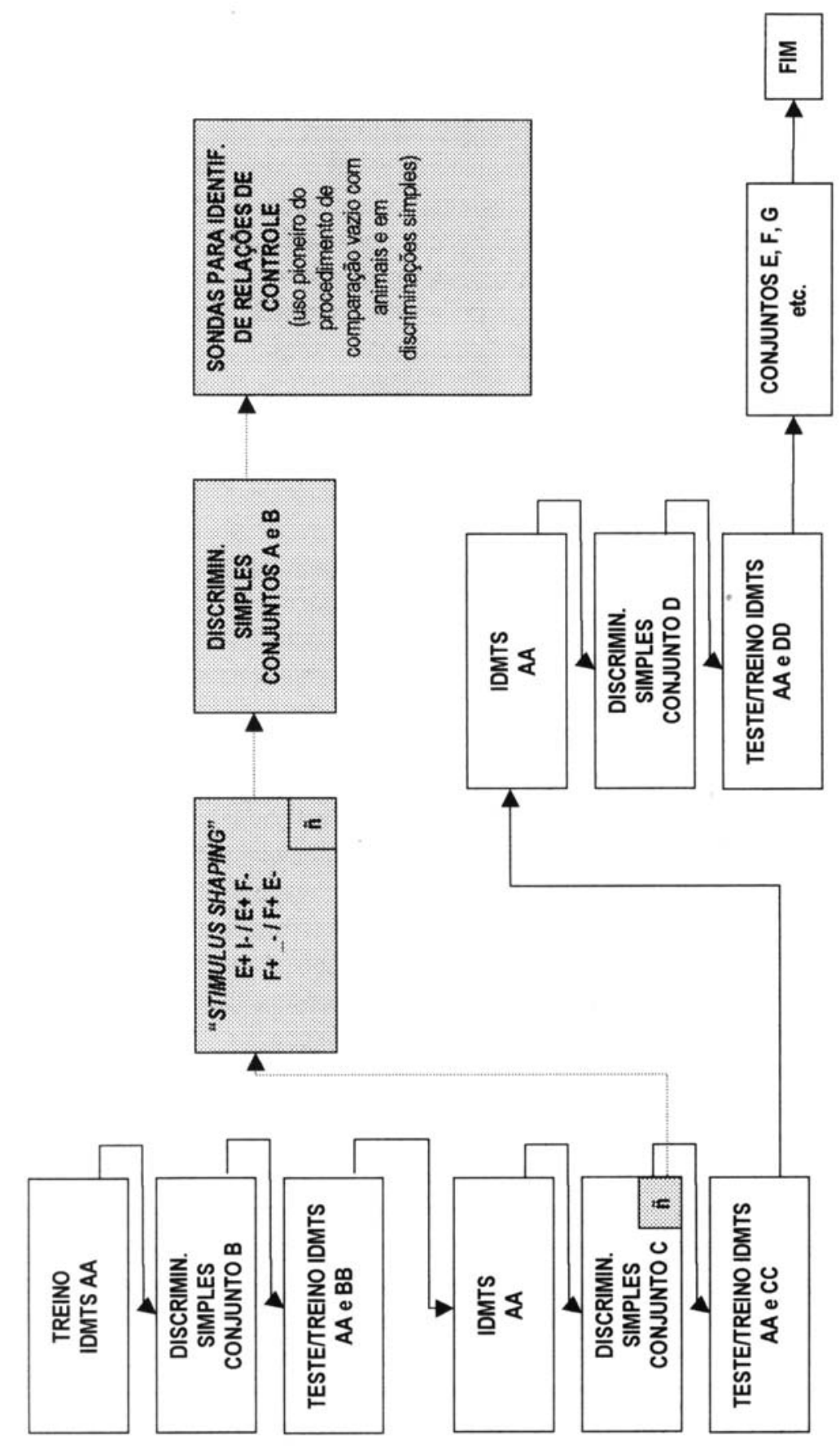

(2)

Figura 4. Plano de pesquisa previsto para o estudo do qual derivou o estudo de Goulart, Mendonça, Barros e Galvão (no prelo) e modificações introduzidas quando da execução do plano. Cada retângulo representa uma etapa do procedimento. Retângulos brancos representam etapas originalmente programadas. Retângulos com preenchimento em cinza representam modificações introduzidas ao plano original. Setas apontam a seqüência das etapas do procedimento. 
O plano experimental foi executado com rigor com o Conjunto A. Quando o procedimento foi repetido com o Conjunto B (que consistia das letras D, E e F), os sujeitos apresentaram dificuldades em discriminar os estímulos "E" e "F". Como análises do desempenho dos sujeitos eram efetuadas a cada sessão, ainda nas primeiras sessões em que essa dificuldade foi confirmada os experimentadores introduziram mudanças no plano original. Dado que um dos objetivos do presente experimento era levar os sujeitos a discriminarem estímulos que apresentam elevado nível de dificuldade (traduzida como uma alta probabilidade de desenvolvimento de generalização entre os estímulos), as letras E e F não podiam ser simplesmente descartadas. Os pesquisadores então, resolveram confrontar diretamente, conforme se pode ver na Figura 4, em discriminações simples simultâneas, os dois estímulos que estavam possibilitando o desenvolvimento de generalização de estímulos. A introdução desse procedimento não produziu mudança no quadro de dificuldade de discriminação. Os dados requeriam novas alterações de procedimento para tornar possível a discriminação. Foi então introduzido um procedimento denominado, de acordo com a literatura, como stimulus shaping. O procedimento consistia no treino de discriminação simples simultânea com o par de estímulos "E" e "F", sendo que o estímulo que funcionava como S+ (a letra "E", por exemplo) era apresentada por inteiro e do outro estímulo (a letra "F", por exemplo) era apresentado apenas um fragmento (uma linha vertical, por exemplo). Quando o critério de seis tentativas corretas consecutivas era atingido, um novo bloco de tentativas era iniciado com o estímulo Sacrescido de mais um fragmento. Esse procedimento era repetido até que o estímulo fosse apresentado integralmente. Em resumo, o procedimento consistia em ressaltar a discrepância entre os estímulos e depois ir reduzindo essa discrepância progressivamente até o ponto em que os sujeitos mostraram dificuldades. Os dados indicaram que quando o terceiro passo na redução progressiva da discrepância era dado, os sujeitos mostravam grande dificuldade de discriminação, embora tivessem discriminado bem os Passos 1 e 2 .

Uma nova pergunta foi então formulada: quais seriam as relações de controle presentes quando os sujeitos mostravam precisão alta no desempenho (por exemplo no Passo 2 do procedimento de stimulus shaping)? Em outras palavras, os sujeitos mostrariam controle por S-, por S+ ou ambos? Essa pergunta, levou a nova modificação no plano experimental, passando a incluir um teste de relações de controle com o procedimento de máscara ou procedimento de comparação vazio (no qual um quadrado branco, ora substitui o $\mathrm{S}+$, ora substitui o $\mathrm{S}-$, com o objetivo de testar o controle exercido por esses estímulos separadamente). Mais detalhes sobre características originais desse procedimento podem ser encontrados em McIlvane, Kledaras, Munson, King, de Rose e Stoddard (1987) e Mcllvane, Munson e Stoddard (1988).

Os resultados da introdução do procedimento da máscara não permitiram obter conclusões precisas a respeito das relações de controle.

Decidiu-se, então, realizar reversões repetidas de discriminações simples com os estímulos tal como apresentados no procedimento de stimulus shaping. Esse procedimento consiste em reverter várias vezes a discriminação simples antes de passar para o próximo passo da construção do estímulo. A introdução desse procedimento não produziu dados sistemáticos e o plano de pesquisa original foi suspenso. Contudo, estudos mais detalhados a respeito da possibilidade de uso do procedimento de "máscara" para avaliação de relações de controle de estímulo em discriminações simples foram conduzidos e relatados por Goulart, Mendonça, Barros, Galvão e McIlvane (2005). Esse estudo produziu dados pioneiros sobre o uso do procedimento de máscara com sujeitos não-humanos e em discriminações simples. O estudo também produziu evidências claras de controle por rejeição (ou controle por S-) em sujeitos não humanos, o que é um tipo de dado relativamente raro na literatura sobre controle de estímulos em sujeitos não-humanos.

A execução do planos de pesquisa acima descrito, bem como do plano de pesquisa do estudo de Barros, Galvão e McIlvane (2002), foi enfaticamente controlada pelos resultados parciais obtidos. A análise do comportamento dos sujeitos era constante e quando o desempenho exibia algum tipo de inadaptação ao procedimento, o plano era revisto. Essa parece ser uma forma de condução de pesquisa próxima à apresentada por Sidman (1960/1976) e Bachrach (1965/1974).

O presente trabalho procurou caracterizar duas posturas diferentes na condução de planos de pesquisa. Em uma delas, o comportamento do experimentador permanece sob controle da execução de seu plano experimental. Noutra postura, o pesquisador efetua análises mais constantes dos dados parciais, passando a introduzir mudanças não programadas inicialmente durante a aplicação do procedimento. O comportamento do pesquisador permanece mais sensível à avaliação dos resultados e seus objetivos mais firmes em torno da construção de determinado repertório, aproximando a unidade de pesquisa de uma unidade de desenvolvimento de procedimentos de ensino, o que justifica a metáfora do laboratório enquanto uma escola. 
Essas são questões de grande relevância para os estudos desenvolvidos na Escola Experimental de Primatas, uma vez que os trabalhos ali desenvolvidos passaram a ser mais claramente ligados a estudos de aplicação que visem a desenvolver técnicas mais adequadas para pesquisas comportamentais com sujeitos humanos com atraso severo no desenvolvimento e com repertório comportamental pobre.

Ainda retornando à questão da condução da pesquisa, De acordo com Bachrach (1965/1974)...

Embora a metodologia do cientista possa parecer casual, há uma concepção global dos objetivos. Incursões no planejamento de aparelhos, discussões e outras agradáveis voltinhas permanecem, contudo, dentro do plano final de conhecimento e descoberta.

Há momentos em que a curiosidade do cientista é estimulada por situações fora do comum ou inexplicáveis, nem sempre fáceis de serem estudadas experimentalmente, mas se constituindo em um estímulo potencial para a pesquisa. (p. 4)

Uma boa descrição da maneira como os dois últimos planos experimentais aqui apresentados foram conduzidos pode ser extraída da discussão apresentada por Luna (1997) sobre o planejamento do processo de pesquisa. Segundo ele,

A partir das primeiras decisões tomadas, abre-se um verdadeiro leque de caminhos alternativos a tomar e o pesquisador deve estar preparado para, ao mesmo tempo, ser sensivel às alterações que se lhe impõem (seja pela lógica do planejamento seja pelos resultados que começa a obter) e manter o equilíbrio metodológico sob o risco de terminar com uma massa de informações que não produzem dados consistentes.

Essa fluidez do processo de pesquisa (que não deve justificar ausência de critérios) torna impraticável e indesejável normatizá-lo. Apesar disto, a experiência indica caminhos (a trilhar ou a evitar) e recursos que podem auxiliar na reflexão que preside o planejamento. (p. 26-27)

\section{REFERÊNCIAS}

Bachrach, A. J. (1965/1974). Introdução à pesquisa psicológica. São Paulo: EPU.

Barros, R. S. \& Galvão, O. F. (2003). Aprendizagem relacional com posições como estímulo em macacos-prego (Cebus apella). Acta Comportamentalia, 11(1), 47-85.

Barros, R. S., Galvão, O. F. \& Fontes, J. C. S. (1996). Um teste de simetria após treino de relações condicionais de posição com macaco Ateles paniscus paniscus. Acta Comportamentalia, 4(2), 181-204.

Barros, R. S., Galvão, O. F. \& McIlvane, W. J. (2002). Generalized identity matching-to-sample in Cebus apella. The Psychological Record, 52, 441-460.

Dias, P. R. P. (1998). Discriminações condicionais com posições como estímulo em Cebus apella. Dissertação de Mestrado. Universidade Federal do Pará. Belém, PA.

Galvão, O. F., Barros, R. S.. Rocha, A. C., Mendonça, M. B. \& Goulart, P. R. K. (2002). Escola Experimental de Primatas. Estudos de Psicologia, 7, 361-370.

Goulart, P. R. K., Mendonça, M. B., Barros, R. S., Galvão, O. F. \& Mcllvane, W. J. (2005). A note on selection and rejection controlling relations in the simple discriminations of capuchin monkeys (Cebus apella). Behavioural Processes, 69(3), 295302.

Luna, S. V. (1997). Planejamento de pesquisa. São Paulo: EDUC.

McGuigan, F. J. (1960/1976). Psicologia experimental: uma abordagem metodológica. São Paulo: EPU.

McIlvane, W. J., Kledaras, J. B., Munson, L. C., King, K. A., de Rose, J. C. \& Stoddard, L. T. (1987). Controlling relations in conditional discrimination and matching by exclusion. Journal of the Experimental Analysis of Behavior, 48, 187-208.

McIlvane, W. J., Munson, L. C. \& Stoddard, L. T. (1988). Some observations on control by spoken words in children's conditional discrimination and matching by exclusion. Journal of Experimental Child Psychology, 45, 472-495.

Rudio, F. V. (1992). Introdução ao projeto de pesquisa científica. Petrópolis: Vozes.

Sidman, M. (1960/1976). Táticas da pesquisa científica: Avaliação dos dados experimentais na psicologia. São Paulo: Brasiliense.

Sidman, M., Rauzin, R., Lazar, R., Cunningham, S., Tailby, W. \& Carrigan, P. (1982). A search for symmetry in the conditional discriminations of rhesus monkeys, baboons, and children. Journal of the Experimental Analysis of Behavior, 37, 23-44.

Sidman, M. \& Tailby, W. (1982). Conditional discrimination vs. matching-to-sample: an expansion of the testing paradigm. Journal of the Experimental Analysis of Behavior, 37, 5-22 


\section{Sobre os autores:}

\section{Romariz da Silva Barros: Doutor}

Olavo de Faria Galvão: Doutor

Departamento de Psicologia Experimental - Programa de Pós-graduação em Teoria e Pesquisa do Comportamento - Universidade Federal do Pará

Aline Cardoso Rocha: Bacharel em Psicologia e Psicóloga

Endereço para correspondência: Romariz Barros - Rod. Arthur Bernardes, 1650 Q6 L15 - Belém, Pará - 66.825-000

(rsb@cpgp.ufpa.br) ou (romarizsb@comcast.net)

\section{Nota dos autores}

A realização desse trabalho foi apoiada pelo $\mathrm{CNPq}$, através de bolsas de Produtividade em Pesquisa do para os dois primeiros autores (processos P301869/2003-0 e P300256/2000-0 respectivamente), bolsa de Iniciação Científica PIBIC/CNPq/UFPA para a terceira autora e financiamentos à pesquisa (processo 584743/2001-7), e pelo National Institute of Health-USA (5 R01 HD39816-03 CFDA \#93.865). 